\title{
Novel heating/cooling stage designed for fluid inclusion microthermometry of large stalagmite sections
}

Article

Accepted Version

Krüger, Y., Hiltbrunner, B., Luder, A., Fleitmann, D. and Frenz, M. (2014) Novel heating/cooling stage designed for fluid inclusion microthermometry of large stalagmite sections. Chemical Geology, 386. pp. 59-65. ISSN 0009-2541 doi: https://doi.org/10.1016/j.chemgeo.2014.08.004 Available at https://centaur.reading.ac.uk/40202/

It is advisable to refer to the publisher's version if you intend to cite from the work. See Guidance on citing.

Published version at: http://dx.doi.org/10.1016/j.chemgeo.2014.08.004

To link to this article DOI: http://dx.doi.org/10.1016/j.chemgeo.2014.08.004

Publisher: Elsevier

All outputs in CentAUR are protected by Intellectual Property Rights law, including copyright law. Copyright and IPR is retained by the creators or other copyright holders. Terms and conditions for use of this material are defined in the End User Agreement.

www.reading.ac.uk/centaur 
Central Archive at the University of Reading

Reading's research outputs online 


\title{
Novel heating/cooling stage designed for fluid inclusion microthermometry of large stalagmite sections
}

\author{
Yves Krüger $^{1,4, *}$, Beat Hiltbrunner ${ }^{2}$, Andres Luder $^{1}$, Dominik Fleitmann ${ }^{3,4,5}$, Martin Frenz ${ }^{1}$ \\ ${ }^{1}$ Institute of Applied Physics, University of Bern, Switzerland \\ ${ }^{2}$ Astronomical Institute, University of Bern, Switzerland \\ ${ }^{3}$ Institute of Geological Sciences, University of Bern, Switzerland \\ ${ }^{4}$ Oeschger Centre for Climate Change Research, University of Bern, Switzerland \\ ${ }^{5}$ present address: Department of Archaeology, School of Archaeology, Geography and Environmental \\ Sciences, University of Reading, United Kingdom
}

\begin{abstract}
Liquid-vapour homogenisation temperatures of fluid inclusions in stalagmites are used for quantitative temperature reconstructions in paleoclimate research. Specifically for this application, we have developed a novel heating/cooling stage that can be operated with large stalagmite sections of up to $17 \times 35 \mathrm{~mm}^{2}$ to simplify and improve the chronological reconstruction of paleotemperature time-series. The stage is designed for use of an oil immersion objective and a high-NA condenser front lens to obtain high-resolution images for bubble radius measurements. The temperature accuracy of the stage is better than $\pm 0.1{ }^{\circ} \mathrm{C}$ with a precision (reproducibility) of $\pm 0.02{ }^{\circ} \mathrm{C}$.
\end{abstract}

Keywords: microthermometry, heating stage, stalagmites, homogenisation temperature, paleotemperature

\section{Introduction}

During past decades stalagmites have become an important archive providing information on natural climate variations in the past (e.g. Fairchild et al., 2006; Lachniet, 2009; McDermott et al., 2004). Stalagmites can grow continuously over thousands of years by precipitation of calcite from the cave drip water and their age can precisely be dated using the uranium-series dating method. In weakly ventilated caves, the cave air temperature is nearly constant throughout the year and is closely related to the mean annual surface temperature outside the cave (Wigley and Brown, 1976). Thus, stalagmite formation temperatures can be used to develop time series of paleotemperature variations. In recent

\footnotetext{
* corresponding author: e-mail: yves.krueger@iap.unibe.ch phone: +41(0)316313709 address: Sidlerstraße 5, CH-3012 Bern
} 
years, different temperature proxies have been proposed to determine the formation temperatures of stalagmites: (i) the combination of $\delta \mathrm{D}$ and $\delta^{18} \mathrm{O}$ of fluid inclusion water and speleothem calcite, respectively (e.g. Schwarcz et al., 1976; McGarry et al., 2004; Vonhof et al., 2006; Zhang et al., 2008; Affolter et al., 2014), (ii) the excess of ${ }^{13} \mathrm{C}-{ }^{18} \mathrm{O}$ containing molecules (so-called 'clumped isotopes') of calcite (Ghosh et al., 2006; Affek et al., 2008), and (iii) the concentration of dissolved noble gases in the fluid inclusion water (Kluge et al., 2008; Scheidegger et al., 2010).

Recently, we have evaluated the applicability of fluid inclusion liquid-vapour homogenisation temperatures as an alternative approach to determine stalagmite formation temperatures (Krüger et al., 2011). The method relies on the measurement of the temperature at which a two-phase liquid-vapour inclusion homogenises to a stable monophase liquid state upon collapse of the vapour bubble. The temperature of the bubble collapse, i.e., the observed homogenisation temperature $T_{h(o b s)}$ depends on the density of the encapsulated drip water and on the volume of the fluid inclusion. $T_{h(o b s)}$ can be measured using a microscope heating/cooling stage. Prior to measuring liquid-vapour homogenisation temperatures in stalagmites, however, the initially monophase liquid inclusions have to be transferred to a stable two-phase system by applying single ultra-short laser pulses to stimulate vapour bubble nucleation in the metastable liquid (Krüger et al., 2007). Since stalagmites grow under atmospheric pressure conditions, the density of the water preserved in the inclusions depends only on the calcite formation temperature. By applying a thermodynamic model that accounts for the effect of surface tension on liquid-vapour homogenisation (Marti et al., 2012) the density of the encapsulated drip water and hence the formation temperature of the stalagmite can be calculated based on the measurement of $T_{h(o b s)}$ and at least one additional measurement of the vapour bubble radius at a known temperature. Previous studies on recent fluid inclusions from the top part of actively growing stalagmites revealed a potential accuracy of this new temperature proxy of approximately $\pm 0.2{ }^{\circ} \mathrm{C}$ (Krüger et al., 2011).

\section{Motivation to develop a novel heating/cooling stage}

Fluid inclusions in stalagmites form during crystal growth (Kendall and Broughton, 1978) and are typically arranged along calcite growth bands. Thus, the inclusions and the surrounding host calcite have the same age, which allows for a precise chronological reconstruction of stalagmite formation temperatures determined from fluid inclusions. In

previous studies performed on a conventional Linkam THMSG 600 heating/freezing stage the 
chronological reconstruction of the temperature data was complicated due to the fact that the maximum sample size is limited to $7 \mathrm{~mm}$ in diameter. Hence, the initially ca. $20 \times 35 \mathrm{~mm}^{2}$ large and 300-400 $\mu \mathrm{m}$ thick stalagmite sections had to be broken into smaller pieces after removing them from the carrier glass that is needed to stabilize the sample during cutting. This means a considerable and time-consuming effort for sample documentation prior to microthermometric measurements. Nevertheless a precise reconstruction of the sections often failed when the sample fractured to tiny pieces upon dissolving the glue (cyanoacrylate) in an acetone bath. Therefore, the main motivation to build a new heating/cooling stage was to be able to examine entire stalagmite sections that no longer need to be removed from the carrier glass but remain fixed on a $0.3 \mathrm{~mm}$ thick glass substrate with $28 \times 48 \mathrm{~mm}^{2}$ standard dimensions.

The second reason to design a new stage was the application of a microscope objective and a condenser front lens with high numerical apertures (NA) to improve the optical resolution and the quality of the vapour bubble images that are used for determining the bubble radius (Spadin et al., in prep.). The bubble images are taken with a CCD camera at known subambient temperatures: commonly at $5.1{ }^{\circ} \mathrm{C}$, when the bubble radius reaches its maximum (Marti et al., 2009). Since conventional heating/freezing stages like the Linkam THMSG 600 allow for microthermometric measurements from -180 up to $600{ }^{\circ} \mathrm{C}$, their design requires the application of long working distance (LWD) optics that, however, exhibit lower numerical apertures than objectives and condenser front lenses with short working distances. For example, the Olympus LMPlanFL 100x LWD objective we use for the Linkam stage has a NA of 0.8 , while the condenser front lens with a working distance of approximately $13 \mathrm{~mm}$ has a NA of approximately 0.4 . For the new heating/cooling stage that was designed for applications in a narrow temperature range between -15 and $35^{\circ} \mathrm{C}$, we wanted to use a 1.3 NA oil immersion objective (Olympus UPLFLN 100x) and a dry short working distance condenser front lens with a NA of 0.9. The application of an oil immersion objective suggests itself due to the fact that we do not polish the stalagmite sections but instead, we use immersion oil to reduce light scattering at the rough surfaces and thus make the sections transparent for microscopic observations in transmission. To illustrate the improvements of the image quality and resolution, Fig. 1 shows a comparison of two microphotographs of the same vapour bubble taken with the new (Fig. 1a) and the old (Fig. 1b) system. In Fig. 1a the bubble image shows a dark ring with high contrast, whereas in Fig. 1b the dark ring appears much broader and blurred due to lower contrast. Based on a simple ray-tracing model, Spadin et al. (in prep.) found that reflection of light at the bubble meniscus results in a bright ring 
surrounding the dark one. The intensity of this bright ring depends on the NA of the objective,

104 which is illustrated in Fig. 1c for the oil immersion objective (NA 1.3) and in Fig. 1d for the LWD objective (NA 0.8 ). The intensity profile in Fig. 1c displays two distinct intensity maxima outside the dark ring, whereas in Fig. 1d the two peaks can hardly be distinguished from the background. In Fig. $1 \mathrm{a}$ and $1 \mathrm{~b}$ the bright outer ring is only partially visible, which is likely due shadow effects occurring in the stalagmite section and resulting in a non-uniform illumination of the vapour bubble.

110 An additional advantage of the oil immersion objective compared to the LWD objective is the 111 smaller focal spot size due to the higher numerical aperture and a significantly higher 112 transmission of the $800 \mathrm{~nm}$ laser wavelength emitted from the Ti:sapphire femtosecond (fs) 113 laser that is used to induce bubble nucleation. This means that for a given energy and duration 114 of the fs-laser pulse, the oil immersion objective provides a much higher pulse intensity in the 115 focus than the LWD objective, and in consequence, allows us to induce vapour bubble 116 nucleation in inclusions that are located up to $250 \mu \mathrm{m}$ below the sample surface.
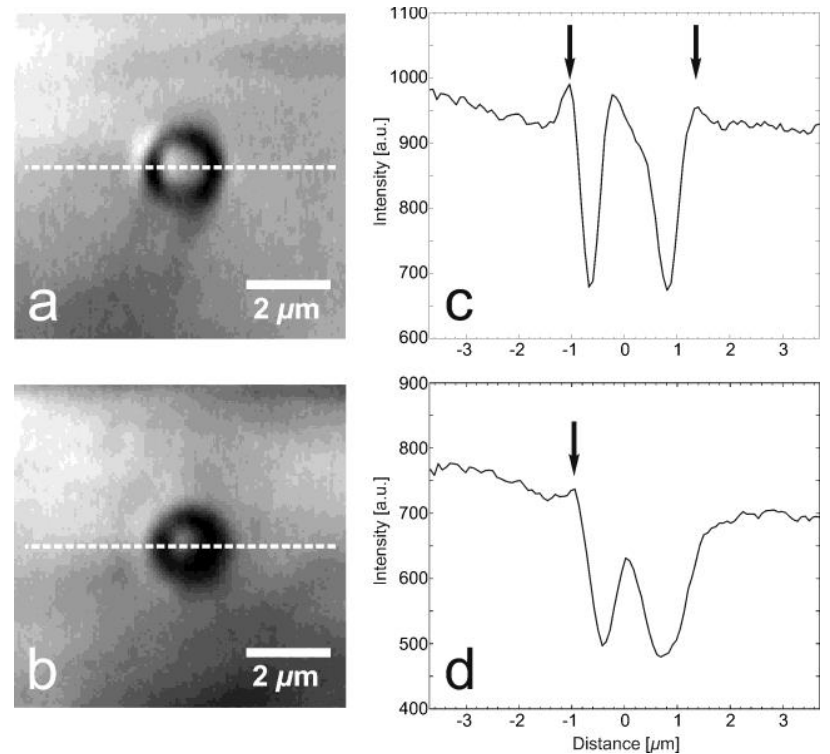

Fig. 1: Comparison of bubble images: a) microphotograph using a 100x oil immersion objective (NA 1.3) and a condenser NA of 0.9. b) microphotograph using a 100x LWD objective (NA 0.8) and a condenser NA of 0.4. c) and d) intensity profiles along the dashed lines indicated in a) and b). Arrows indicate the intensity maximum of the outer bright ring.

\section{Design of the heating/cooling stage}

In the following we describe the design of the novel heating/cooling stage that is 
illustrated in Fig. 2a-e. All components described in the text are labelled in the figures accordingly. The heating/cooling stage is mounted on a Olympus BX51 microscope (Fig. 2c) and its dimensioning complies with the requirements set by the large sample size and the short working distances of the microscope optics. To meet these demands we constructed a large-sized (Ø $116 \mathrm{~mm}$ ) heating/cooling block (A) made from copper, a material with excellent thermal conductivity. The rear side of this copper block features a central recess to bring the condenser front lens (C) close to the sample (Fig. 2b). The sample (III) is placed on the top face of the block (Fig. 2a). The 0.9 NA condenser front lens used has a working distance of $\sim 3.5 \mathrm{~mm}$ and illuminates the sample through a tapered aperture with a final diameter of $1.5 \mathrm{~mm}$ (Fig. 2b). The heating/cooling block (A) comprises (i) a sheathed twincore heating conductor ( 1 ; Thermocoax) of $1.7 \mathrm{~m}$ length and a diameter of $1.5 \mathrm{~mm}$, which is soldered in a spirally routed groove closely below to the surface (Fig. 2b); (ii) a cooling unit (II) consisting of a cooling circuit (2) with inlet and outlet connections for the cooling liquid, a water-ethylene glycol mixture. The cooling unit is placed below the heating conductor; (iii) a Pt-100 thin-film temperature sensor (3; Heraeus) embedded in a slot on the top face of the copper block (Fig. 2a).

The sample (III), i.e., the $0.3 \mathrm{~mm}$ carrier glass with the stalagmite section, is fixed in a $2 \mathrm{~mm}$ thick fibreglass frame that prevents leakage of the immersion oil on the copper block (Fig. 2a). For the preparation of the sample we use UV curable epoxy resins that are inert against the immersion oil and can be applied at sub-ambient temperatures. Prior to the cutting of the sections, the stalagmite sample is fixed on the carrier glass using a low-viscous resin (EpoTek OG603) that closely matches the refractive index of calcite $\left(n_{\varepsilon}=1.486\right)$ in the cured state. The carrier glass is then fixed to the bottom side of the fibreglass frame using a different, higher viscous resin (Epo-Tek OG142). The fibreglass frame can be magnetically attached to the sample holder (V) that is mounted on an $x-y$ translation stage (IV). The translation stage is moved by means of two micrometre gauges (4) with travel lengths of $50 \mathrm{~mm}$ and $25 \mathrm{~mm}$, respectively. The position of the sample can be read off from the scales on the micrometre gauges, which allows for a precise localisation of the analysed fluid inclusions mandatory for the chronological reconstruction of the temperature data. The maximum size of the stalagmite sections that can be scanned with the oil immersion objective is $17 \times 35 \mathrm{~mm}^{2}$.

The application of an immersion objective (D) that is in direct thermal contact with the oil film covering the stalagmite sample requires an active control of the objective temperature to minimise vertical temperature gradients and to achieve faster equilibration of the sample temperature. Therefore, we have developed a copper heating/cooling jacket (B) that allows for 
a precise regulation of the objective temperature. To accomplish an efficient heat transfer, the

161 heating/cooling jacket is attached directly to the inner brass cylinder that houses the objective

162 lenses (D). To this end, we removed the outer protective sleeve of the objective and modified the spring system that protects the front lens from mechanical damage. The cylindrical

164 heating/cooling jacket consists of a heater element (I) that is made up of a coiled twin-core

165 heating conductor (1) embedded between two copper sleeves and an outer cooling unit (II) with inlet and outlet connections (2) for the cooling liquid. The heater element (I) is screwed on the objective (D) and features a $2 \mathrm{~mm}$ spring deflection relative to the cylindrical cooling unit (II) that serves as guidance for the spring suspension of the objective. An insulating sheath (9) made from Polyoxymethylene (POM), finally, encases the heating/cooling jacket. The back aperture of the POM sheath is sealed with a $1 \mathrm{~mm}$ glass window (10) to prevent condensation of moisture on the objective rear lens and within the heating/cooling jacket. The whole assembly is fixed to the microscope frame by means of a detachable single-position nosepiece (VII) with centring screws to align the objective to the optical axis. A lateral through-hole (11, Fig. 2d) in the nosepiece can be used to flush the glass window with nitrogen gas to remove the condensed air moisture from the glass window. The objective temperature, finally, is measured by a Pt-100 thin-film sensor (3) that is placed close to the objective front lens (Fig. 2d).

The sample chamber is placed inside a sealed off aluminium housing (VIII) to minimise condensation of air moisture and thermal effects induced by air circulation. An opening in the base plate (Ø $34 \mathrm{~mm}$ ) provides access to enter the condenser front lens (C) and is sealed off by a V-seal (7) mounted on the outer face of the adapter tube (8) that tightly connects the aperture diaphragm and the front lens of the condenser (Fig. 2e). From above, the objective with the heating/cooling jacket can be entered through an opening ( $\varnothing 60 \mathrm{~mm}$ ) in the centre of the detachable cover plate (5). A V-seal (7) mounted on the POM insulation sheath seals off the port when the objective comes close to the sample. The cover plate is fixed to the housing by means of two clamping levers (6) and thus can be easily and quickly removed to load the sample. Finally, a plug board (VI) in the side wall of the aluminium housing is used as lead-through to connect the lower heating/cooling block (A) to the electric and the hydraulic circuits (Fig. 2a,c). 

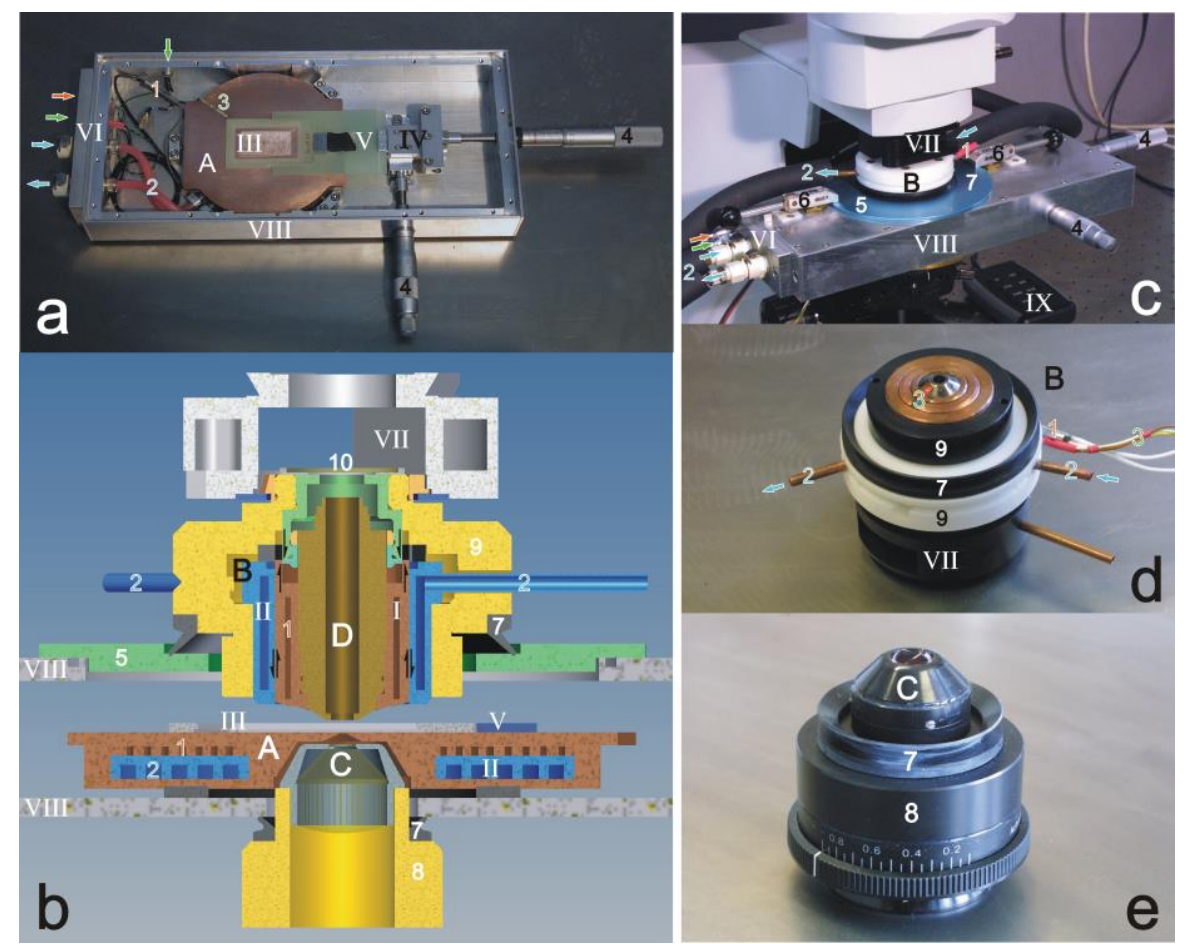

Fig. 2: a) View of the heating/cooling stage with removed cover b) Cross-section through the stage and the objective heating/cooling jacket c) stage mounted on the microscope d) objective with heating/cooling jacket e) condenser assembly.

Legend:

A: heating/cooling block B: objective heating/cooling jacket C: condenser lens D: oil immersion objective.

I: heater element II: cooling element III: sample IV: $x$-y translation stage V: sample holder VI: plug board VII: objective nose piece VIII: stage housing IX remote control.

1: heating conductors 2: cooling circuits 3: Pt-100 sensors 4: micrometer gauge 5: detachable cover plate 6: clamping lever 7: V-seal 8: adapter tube 9: insulating sheath 10: window 11:gas inlet

Connections are indicated by arrows: red for heating conductor, blue for cooling circuit, green for Pt-100 sensor and grey for nitrogen gas.

\section{Mode of operation of the stage}

The twin-core heating conductors (1) in the lower copper block (A) and in the objective jacket (B) are connected to separate power supply units (Elektro Automatik EA-PS 3150-04 B) to enable independent temperature control of the two heating/cooling elements. A cryo-thermostat (Lauda ProLine RP 845) is used to feed the two cooling circuits and provides for a constant temperature and flow rate of the cooling liquid. The stage is operated under permanent circulation of the coolant, while the temperature of the two heating/cooling 
elements is regulated individually by varying the voltage impressed on the heating

214 conductors. The stage reaches a maximum sample temperature that is $50^{\circ} \mathrm{C}$ in excess of the

215 coolant temperature set at the thermostat. Considering the specific application to fluid

216 inclusions in stalagmites and the use of immersion oil, a $50{ }^{\circ} \mathrm{C}$ temperature range of the stage

217 is more than sufficient. The two Pt-100 sensors (3) attached to the lower heating/cooling

218 block and to the microscope objective, respectively, are connected to a four-channel

219 temperature converter (National Instruments). The temperature converter and the two power

220 supply units are connected to a computer via USB interfaces. A LabView ${ }^{\circledR}$ based PID

221 (Propotional-Integral-Derivative) controller is used to regulate the temperature of the two

222 heating/cooling elements. For convenience, the stage can be operated via the function keys of

223 a remote control (IX, Fig. 2c). A flow chart of the temperature control system is shown in Fig.

2243.

225

Fig. 3: Scheme of the temperature control of the heating/cooling stage. For the calibration of the stage additional Pt-100 sensors can be connected to measure the sample temperature and to monitor room temperature variations

\section{Thermal characterisation and temperature calibration of the stage}

To characterise the thermal properties of the heating cooling stage such as precision, accuracy and equilibration times, we used an additional Pt-100 thin-film sensor fixed on a $0.3 \mathrm{~mm}$ glass substrate and embedded in epoxy resin (Fig. 4a). This sensor allows us to measure the sample temperature $\left(T_{3}\right)$ in the centre of the lower copper block, i.e., in the optical path of the microscope. The regular Pt-100 sensor $\left(T_{1}\right)$ embedded in the lower copper block is about $40 \mathrm{~mm}$ off the centre, which means that $T_{3}$ is not equal $T_{l}$ due to lateral thermal gradients. The same applies for the objective temperature $T_{2}$ that is not equal to the 
temperature of the front lens $T_{4}$ (Fig $4 \mathrm{~b}$ ). Since we cannot directly measure the sample and

243 front lens temperatures during fluid inclusion microthermometry, we need a calibration to

244 determine $T_{3}$ and $T_{4}$ based on the two set temperatures $T_{1}$ and $T_{2}$. Furthermore, $T_{4}$ should

245 equal $T_{3}$ to avoid vertical temperature gradients within the sample. We recall that the

246 objective front lens is in contact with sample via the immersion oil. The PID controller is

capable of holding $T_{1}$ and $T_{2}$ constant within $\pm 0.01{ }^{\circ} \mathrm{C}$, which determines the fluctuation of $T_{3}$ and $T_{4}$.

Fig. 4: Positions of temperature measurements for the stage calibration. a) $T_{1}$ : surface temperature of the copper block $40 \mathrm{~mm}$ apart from the sample position, measured with a permanent Pt-100 sensor. $T_{3}$ : sample temperature measured with an additional Pt-100 sensor used only for calibration. b) $T_{2}$ : objective temperature close to the front lens measured with a permanent Pt-100 sensor. $T_{4}$ : temperature of the objective front lens, not measured directly (see text for details).

Fig. 5: Schematic representation of the measurement procedure used to calibrate of the objective front lens

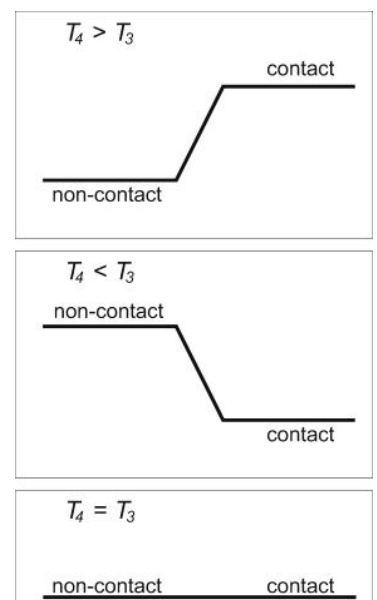


For the calibration of the stage it was not practicable to measure both the front lens temperature $T_{4}$ and the sample temperature $T_{3}$ independently. Instead of measuring $T_{4}$ directly, we only measured $T_{3}$ as a function of $T_{1}$ and minimised the vertical temperature gradient between $T_{3}$ and $T_{4}$ by adjusting the objective set temperature $T_{2}$. In practice, we measured $T_{3}$, first, in a non-contact configuration with the objective front lens about $0.3 \mathrm{~mm}$ above the immersion oil covering the embedded Pt-100 sensor and, subsequently, in a contact configuration with the front lens immersed in the oil and thus in thermal contact with the Pt100 sensor. In this way, we were able to detect thermal gradients between the objective front lens and the sample (Pt-100 sensor) on the basis of the temperature change of $\mathrm{T}_{3}$. By adjusting the objective set temperature $T_{2}$ in repeated measurements, we finally minimised the thermal gradients and thus the change of $T_{3}$ when switching over to the contact configuration. This calibration procedure is illustrated schematically in Fig. 5. Calibration measurements were performed at different sample temperatures $T_{3}$ and for different coolant temperatures $T_{\text {coolant }}$. The results are shown in Fig. 6. The diagram displays the deviation of the two set temperatures, $T_{1}$ and $T_{2}$, from the calibrated sample temperature $T_{3(\text { cal })}\left(\Delta T_{\text {set }}=T_{\text {set }}-T_{3(\text { cal })}\right)$ as function of $T_{3(\mathrm{cal})}$ for coolant temperatures of $0,-5,-10$ and $-15^{\circ} \mathrm{C}$. The relation between $\Delta T_{\text {set }}$ and $T_{3(\text { cal })}$ is nearly linear for both, the lower copper block $\left(T_{1}\right)$ and the objective $\left(T_{2}\right)$. To test our calibration, we repeated the measurements of the sample temperature in the contact configuration. Measurements were taken in $5{ }^{\circ} \mathrm{C}$ increments using a heating/cooling rate of 5 ${ }^{\circ} \mathrm{C} / \mathrm{min}$ and an equilibration time of 15 minutes after each temperature step. Fig. 7 illustrates that the deviation of the measured sample temperatures $T_{3(\text { meas })}$ from the calibration temperature $T_{3(\text { cal })}$ is less than $\pm 0.02{ }^{\circ} \mathrm{C}$, except for some measurements performed with a coolant temperature of $-15^{\circ} \mathrm{C}$, which show a slightly larger deviations above $15^{\circ} \mathrm{C}$. This is due to the limited cooling capacity of the thermostat, which results in a slight increase of $T_{\text {coolant }}$ with increasing stage temperature and larger temperature fluctuations. In addition, Fig. 7 indicates a small hysteresis between heating and cooling runs. Repeated measurements with the same coolant temperature yield a precision (reproducibility) of $T_{3}$ of $\pm 0.01{ }^{\circ} \mathrm{C}$.

The temperature tolerance of the Pt- 100 sensors $(1 / 3$ Class B) used for the calibration is $\pm 0.1^{\circ} \mathrm{C}$ at $0{ }^{\circ} \mathrm{C}$ and $\pm 0.15^{\circ} \mathrm{C}$ at $30^{\circ} \mathrm{C}$. To further improve the accuracy of the sample temperature $T_{3}$ below $\pm 0.1^{\circ} \mathrm{C}$, we used synthetic $\mathrm{H}_{2} \mathrm{O}$ and $\mathrm{H}_{2} \mathrm{O}-\mathrm{CO}_{2}$ fluid inclusions for absolute temperature calibrations. The use of synthetic fluid inclusions allows us to compare our measurements with well-known reference temperatures, namely the melting temperature of ice at $0.0{ }^{\circ} \mathrm{C}$ and the critical homogenisation of $\mathrm{CO}_{2}$ in the $\mathrm{H}_{2} \mathrm{O}-\mathrm{CO}_{2}$ system at $31.42{ }^{\circ} \mathrm{C}$ (Morrison 1981). Measurements were preformed with different coolant temperatures yielding 
a precision of $\pm 0.02{ }^{\circ} \mathrm{C}$ and a slight offset of $T_{3}$ to lower temperatures: $-0.1^{\circ}$ at $0.0^{\circ} \mathrm{C}$ and -

$2980.15^{\circ}$ at $31.42^{\circ} \mathrm{C}$. Using these offset values for a correction of the calibration, we can achieve a temperature accuracy of the heating/cooling stage of approximately $\pm 0.05^{\circ} \mathrm{C}$.

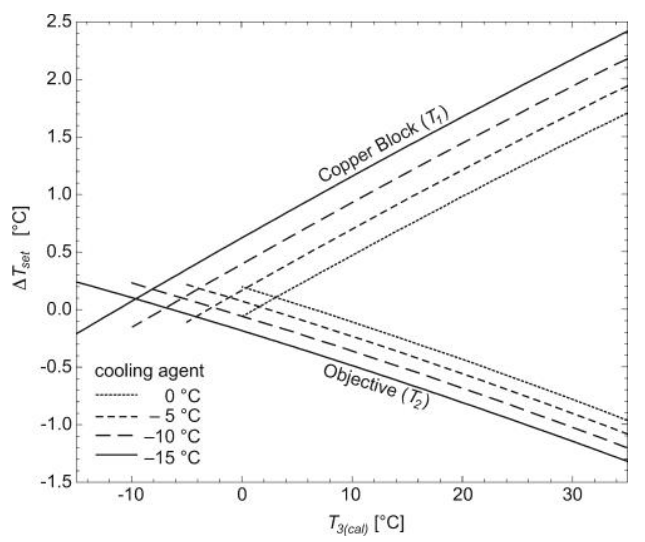

Fig 6: Deviation of the set temperatures $T_{1}$ and $T_{2}$ from the calibrated sample temperature $T_{3(\mathrm{cal})}$ for different coolant temperatures indicated by colours (see text for details).

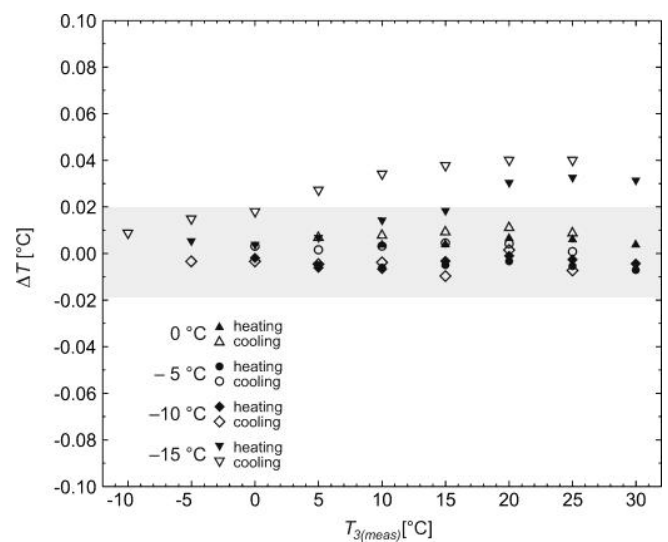

Fig. 7: Calibration check illustrating the deviation of the measured sample temperature value $T_{3(\text { meas })}$ from the calibration $T_{3(\mathrm{cal})}$. Filled symbols denote measurements upon heating, open symbols upon cooling. Colours indicate different coolant temperatures.

The measurements of the ice melting temperature have also shown that absorption of light in the sample can increase $T_{3}$ by up to $0.05^{\circ} \mathrm{C}$, in spite of using a heat-absorbing IRfilter (Schott KG5 IR) in the illumination light path. In consequence of the absorption the effective sample temperature is higher than predicted by the calibration, which results in an underestimation of the ice melting temperature. To deal with this potential uncertainty we are working with a pre-defined setting of the light intensity and of the field diaphragm for sample illumination. Finally, we investigated the effect of room temperature fluctuations on the sample temperature. Both $T_{3}$ and the room temperature were measured with Pt-100 sensors. The results of these measurements indicate that a change in room temperature of $1{ }^{\circ} \mathrm{C}$ affects the sample temperature by less than $0.01{ }^{\circ} \mathrm{C}$, which is a negligible error in an air-conditioned lab with room temperature fluctuations of less than $\pm 2{ }^{\circ} \mathrm{C}$.

Besides precision and accuracy we also analysed the dynamic properties of the stage, namely the temperature equilibration times. The equilibration time $t_{\mathrm{eq}}$ denotes the time lag of the system to reach a stable temperature state after a temperature change $\Delta T$. The time at which the set temperature reaches its new value serves as reference time $t_{0}$. Equilibration times were measured for $T_{1}$, the temperature of the lower heating/cooling block, for $T_{2}$, the 
objective temperature and for the sample temperature $T_{3}$. Figure 8 illustrates the nominal

319 (dashed lines) and the measured temperature trends (solid lines) of $T_{1}, T_{2}$ and $T_{3}$ as a function

320 of time for different temperature changes $\Delta T$ and heating rates. The diagrams show that $T_{1}$

321 and $T_{2}$ slightly over-shoot the set temperatures after heating is stopped and then return to their

322 set values. The equilibration times $t_{\mathrm{eq}}$ of $T_{1}$ and $T_{2}$ are very similar and depend only on the

323 heating rate $\left(\sim 10 \mathrm{~s}\right.$ at $1{ }^{\circ} \mathrm{C} / \mathrm{min}, \sim 20 \mathrm{~s}$ at $\left.10{ }^{\circ} \mathrm{C} / \mathrm{min}\right)$. The sample temperature $T_{3}$, in contrast,

324 approaches its set temperature asymptotically from below with a considerable time lag. The

325 time the system needs to reach a stable sample temperature is too long for practical use (up to

326360 seconds) and therefore we defined three time markers $t_{1}, t_{2}$ and $t_{3}$ at which the sample

327 temperature is $0.1,0.05$ and $0.02{ }^{\circ} \mathrm{C}$, respectively, below the final sample temperature $T_{3}(e q)$.

328 Fig. 8 shows that $t_{1}, t_{2}$ and $t_{3}$ depend on the heating rate as well as on the temperature change

$329 \Delta T$. With respect to fluid inclusion measurements $\mathrm{t}_{1}$ implies a temperature overestimation of

$3300.1^{\circ} \mathrm{C}, \mathrm{t}_{2}$ of $0.05{ }^{\circ} \mathrm{C}$ and $\mathrm{t}_{3}$ of $0.02{ }^{\circ} \mathrm{C}$. This means that the accuracy of the $T_{h}$ measurements

331 also depends on the measuring routine that needs to be adjusted accordingly.

In practise, we use a rate of $10^{\circ} \mathrm{C} / \mathrm{min}$ to heat the stage to a temperature that is approximately $2-3{ }^{\circ} \mathrm{C}$ below the expected homogenisation temperature. After an equilibration time of 60-90 seconds, further heating is accomplished with a rate of $1{ }^{\circ} \mathrm{C} / \mathrm{min}$. Close to the homogenisation, finally, when the vapour bubble becomes very small, the temperature is increased stepwise in $0.05{ }^{\circ} \mathrm{C}$ increments until $T_{h}$ is reached. During this last phase of the measurement the sample temperature closely follows the set temperature. 

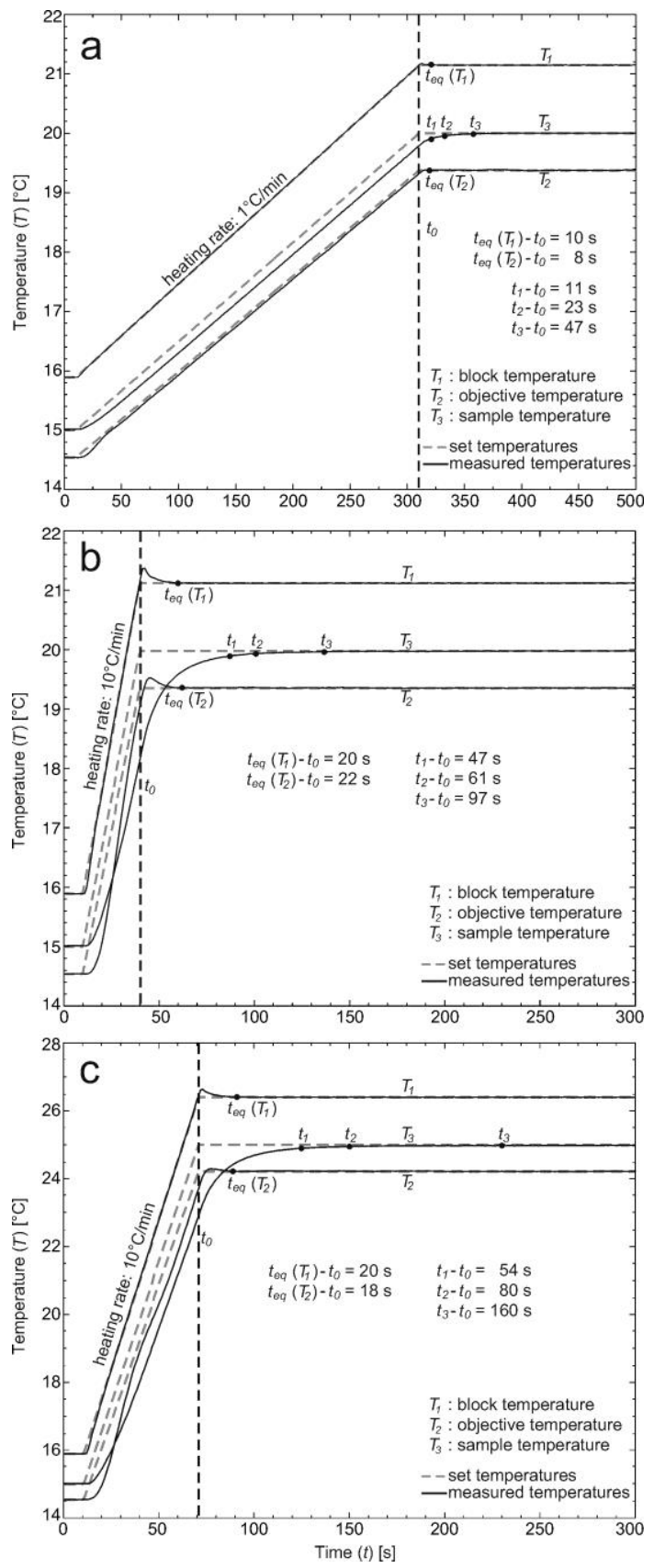

Fig. 8: Temperature-time plots illustrating the equilibration times of $T_{1}, T_{2}$ and $T_{3}$ after temperature increases: a)

$5{ }^{\circ} \mathrm{C}$ at a heating rate of $1{ }^{\circ} \mathrm{C} / \mathrm{min}$ b) $5{ }^{\circ} \mathrm{C}$ at a heating rate of $10^{\circ} \mathrm{C} / \mathrm{min}$ and c) $10{ }^{\circ} \mathrm{C}$ at a heating rate of

$10^{\circ} \mathrm{C} / \mathrm{min}$. Dashed lines indicate the set temperatures and solid lines represent the measured temperature trends. 


\section{Conclusions}

Liquid-vapour homogenisation of fluid inclusions in stalagmites is a promising new approach to accurately reconstruct paleotemperature variations with high temporal resolution. For this specific application, we have developed a novel heating/cooling stage for operation with large stalagmite sections and high-NA optics. With a temperature accuracy well below $\pm 0.1{ }^{\circ} \mathrm{C}$ and a precision of $\pm 0.02{ }^{\circ} \mathrm{C}$ the stage meets the requirements for fluid inclusion measurements in this temperature range. In a next step of development we will factor the dynamic properties of the stage into the PID temperature control to further reduce the equilibration times after large temperature changes and thus, to increase the efficiency of the $T_{h}$ measurements.

\section{Acknowledgements}

The authors thank N. Jaussi, A. Jenk and A. Friedrich for manufacturing the components of the stage and for helpful discussions.

This work is part of the SINERGIA project "STALCLIM - Multi-proxy climatic and environmental reconstructions from stalagmites from Switzerland, Turkey, Arabia and India“ (SNF grant: CSRI22-132646/1)

\section{References:}

Affek, H. P., Bar-Matthews, M., Ayalon, A., Matthews, A., and Eiler, J. M., 2008. Glacial/interglacial temperature variations in Soreq cave speleothems as recorded by 'clumped isotope' thermometry. Geochim. Cosmochim. Ac., 72, 5351-5360.

Affolter, S., Fleitmann, D., and Leuenberger, M., 2014. New on-line method for water isotope analysis of speleothem fluid inclusions using laser absorption spectroscopy (WS-CRDS). Clim. Past Discuss., 10, 429-467,

Fairchild, I.J., Smith, C.L., Baker, A., Fuller, L., Spötl, C., Mattey, D. and McDermott, F., 2006. Modification and preservation of environmental signals in speleothems. Earth Sci. Rev. 75, 105-153.

Ghosh, P., Adkins, J., Affek, H., Balta, B., Guo, W., Schauble, E.A., Schrag, D., and Eiler, J.M., $2006 .{ }^{13}$ C- ${ }^{18} \mathrm{O}$ bonds in carbonate minerals: A new kind of paleothermometer. Geochim. Cosmochim. Ac., 70, 1439-1456. 
Kluge, T., Marx, T., Scholz, D., Niggemann, S., Mangini, A., and Aeschbach-Hertig, W., 2008. A new tool for palaeoclimate reconstruction: Noble gas temperatures from fluid inclusions in speleothems. Earth Planet. Sc. Lett., 269, 407-414.

Krüger, Y., Stoller, P., Rička, J., and Frenz, M., 2007. Femtosecond lasers in fluid-inclusion analysis: overcoming metastable phase states. Eur. J. Mineral., 19, 693-706.

Krüger, Y., Marti, D., Hidalgo Staub, R., Fleitmann, D., and Frenz, M., 2011. Liquid-vapour homogenisation of fluid inclusions in stalagmites. Evaluation of a new thermometer for paleoclimate research: Chem. Geol., 289, 39-47.

Lachniet, M.S., 2009. Climatic and environmental controls on speleothem oxygen-isotope values. Quaternary Sci. Rev., 28(5-6), 412-432.

Marti, D., Krüger, Y., Frenz, M., 2009: Fluid inclusion liquid-vapour homogenization in the vicinity of the density maximum of aqueous solutions. ECROFI XX Abstract

Marti, D., Krüger, Y., Fleitman, D., Frenz, M., and Rička, J., 2012. The effect of surface tension on liquid-gas equilibria in isochoric systems and its application to fluid inclusions. Fluid Phase Equilibr., 314, 13-21.

Formatted: German (Switzerland)

McDermott, F., 2004. Palaeo-climate reconstruction from stable isotope variations in speleothems: a review. Quaternary Sci. Rev., 23, 901-918.

McGarry, S., Bar-Matthews, M., Matthews, A., Vaks, A., Schilman, B. and Ayalon, A., 2004. Constraints on hydrological and paleotemperature variations in the Eastern Mediterranean region in the last $140 \mathrm{ka}$ given by the delta D values of speleothem fluid inclusions. Quaternary Sci. Rev., 23, 919-934.

Morrison, G., 1981. Effect of water upon the critical points of carbon dioxide and ethane. J. Phys. Chem., 85: 759-761.

Scheidegger, Y., Baur, H., Brennwald, M.S., Fleitmann, D., Wieler, R., Kipfer, R., 2010. Accurate analysis of noble gas concentrations in small water samples and its application to fluid inclusions in stalagmites. Chem. Geol., 272, 31-39.

Schwarcz, H.P., Harmon, R.S., Thompson, P., Ford, D.C., 1976. Stable isotope studies of fluid inclusions in speleothems and their paleoclimatic significance. Geochim. Cosmochim. Ac., 40, 657-665.

Spadin, F., Marti, D., Hidalgo Staub, R., Krüger, Y., Rička, J., Fleitmann, D., Frenz, M., in prep. Accuracy of stalagmite formation temperatures determined from vapour bubble radius measurements in fluid inclusions.

Vonhof, H.B., van Breukelen, M.R., Postma, O., Rowe, P.J., Atkinson, T.C., Kroon, D., 2006. A continuousflow crushing device for on-line ${ }^{T{ }^{2}} \mathrm{H}$ analysis of fluid inclusion water in speleothems. Rapid Commun. Mass Sp., 20, 2553-2558.

Wigley T.M.L. \& Brown M.C., 1976 - The physics of caves. In: Ford T.D. \& Cullingford C.H.D. (Eds.), The Science of Speleology. New York: Academic Press: 329-358.

Zhang, R., Schwarcz, H. P., Ford, D. C., Schroeder, F. S., and Beddows, P. A., 2008. An absolute paleotemperature record from 10 to $6 \mathrm{Ka}$ inferred from fluid inclusion $\mathrm{D} / \mathrm{H}$ ratios of a stalagmite from Vancouver Island, British Columbia, Canada. Geochim. Cosmochim. Ac., 72, 1014-1026. 